\title{
Quality of Life in Chronic Hemodialysed Patients
}

\section{Yaya Kane*}

Department of Nephrology, Assane Seck University, Ziguinchor, Senegal

\begin{abstract}
Introduction: End-stage renal failure has a significant impact on patients' daily lives, which can be measured by quality of life questionnaires. The objective of this study was to assess the health condition related to quality of life in hemodialysed patients in three semi-urban hospitals of Senegal and to determine the factors associated with it.

Patients and methods: During an observational, transversal, descriptive and analytical study conducted for 2 months, between March 1st and April 30th, 2016, the patients' records, in 3 cities, maintained under regular hemodialysis for at least 3 months and at least 18 years old, have been analysed. The health-related quality of life assessment was executed by an interview with patients using the French version of the KDQOL SF (Kidney Disease Quality of Life Short Form) 1.3 questionnaire. Association levels between health domain values and sociodemographic, clinical and biological criteria were investigated using non-parametric Wilcoxon or Kruskal-Wallis tests where 2 or more groups are compared.

Results: We included 79 out of 94 chronic hemodialysed patients during the study period. Sixty-four patients (64) effectively participated in the study. The average age was $43.3 \pm 14.9$ years. The KDQOL SF 36 questionnaire was completed by 64 patients. Among them eight patients did not answer the question which assesses the quality of sexual activity. In Saint Louis, the field that had the lowest score was "General Health" (54.9), and the one with the highest score was "Limitations due to mental state" with 92.8. In the Tambacounda's unit, the lowest score was in the "Limitations due to physical condition" side (41.0), and the highest score was in the "Life and relationships with others" field at 68.0. According to the KDQOL, the "Professional Status" dimension had the lowest score and the "Encouragements received from the dialysis team" the highest score in Kaolack and Saint-Louis whereas in Tambacounda the "Professional Status" dimension had the lowest score (16.0) and that "Quality of the entourage" the highest score (87.7). Women were significantly better (93.8) than men (83.3) compared to the "Dialysis Staff Incentives" category $(p=0.02)$. Married patients scored significantly lower, compared to unmarried patients, in the "Sexual Function" field (55.8 versus 96.1, $p=0.006)$ and "Patient's Satisfaction" (74.8 vs. 87.2; $p=0,01)$.
\end{abstract}

Conclusion: Studies of the hemodialysed patients' quality of life in semi-urban settings are rare in sub-Saharan Africa. This allows us to note a diversity of quality of life according to geographical areas.

Keywords: Hemodialysis, Quality of life; Risk factors

\section{Introduction}

Quality of Life related to Health (QLrH) is the idea, the opinion of a people, of his perception, of his experience, of his health, in close connection with his affect, his beliefs, and his representations. It is defined by the WHO as "the perception that a people has of his place in existence, in the context of the culture and the system of values in which he lives, in relation to his goals, his expectations, his norms, and his worries [1]. In the last 30 years, hemodialysis has seen major therapeutic advances, thus improving the prognosis for chronic renal failure [2]. The lengthening of survival in chronic hemodialysed patients creates new challenges in these patients' treatment. The question of quality of life related to the health of hemodialysis is particularly acute [2-5]. Evaluating QLrH is a major public health issue in chronic diseases in general and in chronic hemodialysed patients in particular. In sub-Saharan Africa, to our knowledge, few studies have examined the quality of life of hemodialysed patients. In Senegal, Cisse et al. [6] were interested in QLrH and its particularities in chronic hemodialysed patients living in urban areas. It is in this sense that we carried out this study in three regions of Senegal in a semi-urban environment. The objectives of this study were to evaluate the chronic hemodialysed patients' quality of life in the city of Tambacounda, Kaolack, and Saint Louis on the one hand and on the other to determine the factors associated with it.

\section{Methodology}

It was an observational, transversal study with descriptive and analytical aims. It was carried out over four months from 1 February to 31 May 2016 in three regional hemodialysis units (Tambacounda (east of Senegal), Kaolack (center of Senegal) and Saint Louis (north of senegal). All patients under hemodialysis for at least three months and at least 18 years of age have been included. Patients who did not consent, who were aphasic or who had dementia were not included. The KDQOL-SF questionnaire, which combines the SF-36 (Short Form-36) and KDQOL questionnaires, was used to collect the data. This questionnaire explores the eight (8) dimensions of the SF-36 (generic questionnaire) and the 12 dimensions of KDQOL, the latter providing information on the impact of chronic kidney disease on quality of life. The included patients were invited to answer the questionnaire KDQOL-SF 1.3 (Table 1), French version, helped by an investigator, after having given their consent. The interview took place during the hemodialysis session. At the end of the interview, the patient's medical record and his dialysis record were used to finalize the collection of information. Answers to the KDQOL SF 1.3 questionnaire

${ }^{*}$ Corresponding author: Yaya Kane, Department of Nephrology, Assane Seck University, Ziguinchor, Senegal, Tel: 002217750021 65; E-mail: yayuskanus@yahoo.fr

Received: August 14, 2019; Accepted: September 28, 2019; Published: October 03, 2019

Citation: Kane Y (2019) Quality of Life in Chronic Hemodialysed Patients. J Nephrol Ther 9: 334.

Copyright: (c) 2019 Kane $Y$. This is an open-access article distributed under the terms of the Creative Commons Attribution License, which permits unrestricted use, distribution, and reproduction in any medium, provided the original author and source are credited. 


\begin{tabular}{|c|c|c|}
\hline Items & SF-36 & KDQOL \\
\hline 1 & Physical Activity & Symptoms/Problems \\
\hline 2 & Limitations Due to Physical Activity & Effects of Kidney Disease \\
\hline 3 & Physical Pain & Burden of Kidney Disease \\
\hline 4 & Life in relation with others & Professional status \\
\hline 5 & Psychic health & Cognitive function \\
\hline 6 & Limitation due to the psychic state & Quality of the entourage \\
\hline 7 & Vitality & Quality of sexual activity \\
\hline 8 & Perceived health & Sleep \\
\hline 9 & & Friendly and family relations \\
\hline 10 & & Incentives received from the dialysis team \\
\hline 11 & & Patient satisfaction \\
\hline 12 & & Overall health \\
\hline KDQOL-SF-36 & 8 items SF-36 & $12 \mathrm{KDQOL}$ domains \\
\hline
\end{tabular}

Table 1: KDQOL-SF-1.3 score French version.

were included in the KDQOL SF 1.3 scoring program of the Division of Internal Medicine and Health Research Services of the University of Los Angeles, California (UCLA), reported on an Excel table, with the rest of the socio-demographic, clinical, paraclinical and therapeutic data and analyzed by Epi-Info version 3.5.4. non-parametric tests of Wilcoxon or Kruskal-Wallis were used as statistical tests. A difference was considered statistically significant from a threshold of $\mathrm{p}<0.05$.

\section{Results}

We included 79 out of 94 chronic hemodialysed patients during the study period. Sixty-four patients (64) effectively participated in the study after excluding 15 of which $25(39.0 \%)$ in Tambacounda, 25 $(39.0 \%)$ in Kaolack and $14(21.8 \%)$ in Saint-Louis. The mean age was $43.3 \pm 14.9$ years with a sex ratio of 0.88 . Other socio-demographic characteristics are shown in Table 2.

The average duration of hemodialysis was $25.2 \pm 18.9$ months. Clinically 42 patients $(66 \%)$ had an arteriovenous fistula. Fifteen patients (25\%) had residual diuresis less than or equal to $150 \mathrm{ml} / 24 \mathrm{~h}$. The average hemoglobin level was $8.1 \mathrm{~g} / \mathrm{dl}$.

The KDQOL SF 36 questionnaire was completed by 64 patients. Of these, eight patients did not answer the question assessing the quality of sexual activity. By studying the domains of the KDQOL and SF-36 questionnaires, the scores were variable according to the unit. The SF-36 score according to the hemodialysis unit is shown in Table 3. In Saint Louis, the field with the lowest score was "General Health" (54.9), and the one with the highest score was "Mental State Limitations" with 92.8 (Table 3). At the unit of Tambacounda, the lowest score concerned the "limitations due to the physical state" field (41.0), and the highest score concerned the field of "Life and relationship with others" with 68.0 (Table 3).

According to the KDQOL, the "Professional Status" field had the lowest score and the "Encouragement received from the dialysis team" the highest score in Kaolack and Saint-Louis whereas in Tambacounda the "Professional Status" field had the lowest score (16.0) and that "Quality of entourage" the highest score (87.7) (Table 4).

Analytically, patients under the age of 35 had a better appreciation of their sexual activity $(80.5, \mathrm{p}=0.02)$. Women felt more encouraged by the dialysis team (93.8, $\mathrm{p}=0.02$ ). Depending on the level of study, the scores for the "Encouragement received from the dialysis team", "Patient satisfaction" and "General health" fields were significantly higher (95.0; 81.5 and 69.3 respectively) in patients who had a level of Koranic, primary or out-of-school population $(n=45)$, compared to

\begin{tabular}{|c|c|}
\hline Characteristics & n (\%) \\
\hline \multicolumn{2}{|l|}{ Gender } \\
\hline Female 34 (54.1) & $34(54,1)$ \\
\hline Male $30(46.9)$ & $30(46,9)$ \\
\hline \multicolumn{2}{|l|}{ Marital status } \\
\hline Single 7 (19.9) & $7(19,9)$ \\
\hline Married 51 (79.7) & $51(79,7)$ \\
\hline Divorced 2 (3.1) & $2(3,1)$ \\
\hline Widower/Widow 4 (6.3) & $4(6,3)$ \\
\hline \multicolumn{2}{|l|}{ Religion } \\
\hline Muslim & $61(95,3)$ \\
\hline Christian 2 (3.1) & $2(3,1)$ \\
\hline Animist 1 (1.6) & $1(1,6)$ \\
\hline \multicolumn{2}{|l|}{ Level of study } \\
\hline Not Schooled & $19(29,7)$ \\
\hline Koran $16(25.0)$ & $16(25,0)$ \\
\hline Primary 10 (15.6) & $10(15,6)$ \\
\hline Secondary 14 (21.9) & $14(21,9)$ \\
\hline Superior 5 (7.8) & $5(7,8)$ \\
\hline \multicolumn{2}{|l|}{ Sector of professional activity } \\
\hline Student 2 (3.2) & $2(3,2)$ \\
\hline Private or informal sector $26(40.6)$ & $26(40,6)$ \\
\hline Public Service 5 (7.8) & $5(7,8)$ \\
\hline
\end{tabular}

Table 2: Summary of socio-demographic characteristics of patients in 3 hemodialysis units in Senegal from February $1^{\text {st }}$ to May $31^{\text {st }}, 2016$.

those with secondary or higher education $(74.3 ; 67.5 ; 54.2 ; \mathrm{p}<0.001$; $p=0.002 ; p=0.004$; respectively). In the field of "patient satisfaction" and "quality of sexual activity", married patients $(n=51)$ had significantly lower scores than those who were not $(\mathrm{p}=0.006 ; \mathrm{p}=0.01$ respectively) while on the professional plan, there was no difference statistically significant in the KDQOL domains between the group of patients who reported having and maintaining a professional activity and the one who reported having none. With the exception of the "physical pain" dimension, in all domains explored by SF 36 , statistically significant differences were found between dialysis units (Table 5) whereas according to KDQOL, only the "cognitive function" dimension had an average in Kaolack statistically higher than other units (Table 6).

Clinically, there was no statistically significant difference in the KDQOL field between the group of patients with permanent access (arteriovenous fistula, tunnelled catheter, $n=47$ ) and the group of those 


\begin{tabular}{|c|c|c|c|}
\hline \multirow[t]{2}{*}{ Items } & \multicolumn{3}{|c|}{ Cities } \\
\hline & Kaolack $(n=25)$ & St Louis $\quad(n=14)$ & Tambacounda $(n=25)$ \\
\hline Physical functioning & 76.2 & 70.3 & 51.2 \\
\hline Limitations due to physical condition & 25.0 & 62.5 & 41.0 \\
\hline Physical pain & 72.5 & 58.5 & 57.6 \\
\hline General Health & 64.2 & 54.9 & 46.7 \\
\hline Mental health & 80.4 & 66.8 & 63.3 \\
\hline Limitations due to mental state & 84.0 & 92.8 & 46.6 \\
\hline Life and relationship with others & 82.5 & 85.7 & 68.0 \\
\hline Vitality & 38.7 & 67.5 & 54.3 \\
\hline Physical Summary Score (SRP) & 38.0 & 42.3 & 39.0 \\
\hline Mental score summary (SRM) & 53.5 .0 & 53.6 & 45.0 \\
\hline
\end{tabular}

Table 3: Average Scores of SF 36 field in the 3 Hemodialysis units.

\begin{tabular}{|c|c|c|c|}
\hline \multirow[t]{2}{*}{ Items } & \multicolumn{3}{|c|}{ Cities } \\
\hline & Kaolack & Saint Louis & Tambacounda \\
\hline Symptoms/Problems & 78.8 & 73.0 & 74.9 \\
\hline Effects of kidney disease & 55.3 & 54.7 & 60.2 \\
\hline Burden of kidney disease & 39.0 & 39.7 & 25.5 \\
\hline Professional status & 36.0 & 39.2 & 16.0 \\
\hline Cognitive function & 85.0 & 73.3 & 75.2 \\
\hline Quality of the environment & 86.4 & 85.7 & 87.7 \\
\hline Quality of sexual activity (§) & 66.0 & 52.7 & 61.3 \\
\hline Sleep & 67.7 & 67.6 & 62.1 \\
\hline Friendly and family relations & 70.6 & 82.1 & 73.1 \\
\hline Incentives received from the dialysis team & 92.5 & 88.3 & 85.5 \\
\hline Patient satisfaction & 83.3 & 77.3 & 71.3 \\
\hline Overall health & 60.8 & 71.4 & 65.2 \\
\hline
\end{tabular}

Table 4: Average scores of the $12 \mathrm{KDQOL}$ field in the 3 hemodialysis units.

\begin{tabular}{|c|c|c|c|c|c|}
\hline Items & $\begin{array}{c}\text { Kaolack } \\
n=25\end{array}$ & $\begin{array}{c}\text { Saint Louis } \\
n=14\end{array}$ & Tambacounda $n=25$ & Overall average & $\mathbf{p}$ \\
\hline Physical functioning & 76.2 & 70.3 & 51.2 & 65.1 & 0.03 \\
\hline limitations due to physical condition & 25.0 & 62.5 & 41.0 & 39.4 & 0.03 \\
\hline Physical pain & 72.5 & 58.5 & 57.6 & 63.6 & 0.2 \\
\hline General Health & 64.2 & 54.9 & 46.7 & 55.3 & 0.02 \\
\hline Mental health & 80.4 & 66.8 & 63.3 & 70.8 & 0.002 \\
\hline Limitations due to mental state & 84.0 & 92.8 & 46.6 & 71.3 & $<0.001$ \\
\hline life and relationship with others & 82.5 & 85.7 & 68.0 & 77.5 & 0.03 \\
\hline Vitality & 38.7 & 67.7 & 54.3 & 50.7 & 0.002 \\
\hline
\end{tabular}

Table 5: Influence of the dialysis' place on the QLrH, according to the SF36 questionnaire in the 3 hemodialysis units.

\begin{tabular}{|c|c|c|c|c|c|}
\hline Items/Cities & Kaolack & Saint Louis & Tambacounda & Overall average & $\mathbf{P}$ \\
\hline Symptoms/Problems & 78.8 & 73.0 & 74.9 & 76.0 & 0.4 \\
\hline Effects of kidney disease & 55.3 & 54.7 & 60.2 & 57.1 & 0.7 \\
\hline Burden of kidney disease & 39.0 & 39.7 & 25.5 & 33.9 & 0.06 \\
\hline Professional status & 36.0 & 39.2 & 16.0 & 28.9 & 0.1 \\
\hline Cognitive function & 85.0 & 73.3 & 75.2 & 78.6 & 0.04 \\
\hline Quality of the environment & 86.4 & 85.7 & 87.7 & 86.7 & 0.9 \\
\hline Quality of sexual activity $(\S)$ & 66.0 & 52.7 & 61.3 & 61.6 & 0.6 \\
\hline Sleep & 67.7 & 67.6 & 62.1 & 65.5 & 0.5 \\
\hline Friendly and family relations & 70.6 & 82.1 & 73.1 & 73.4 & 0.2 \\
\hline Incentives received from the dialysis team & 92.5 & 88.3 & 85.5 & 88.6 & 0.2 \\
\hline Patient satisfaction & 83.3 & 77.3 & 71.3 & 77.3 & 0.06 \\
\hline Overall health & 60.8 & 71.4 & 65.2 & 64.8 & 0.2 \\
\hline \multicolumn{6}{|c|}{$\mathrm{n}=56$} \\
\hline
\end{tabular}

Table 6: Influence of the dialysis' place on the QLrH, according to the KDQOL questionnaire in the 3 hemodialysis units.

with temporary access. Patients with residual diuresis less than or equal to $500 \mathrm{ml}(\mathrm{n}=43)$ had significantly lower average scores in four areas of KDQOL than those with residual diuresis superior to $500 \mathrm{ml}(\mathrm{n}=21)$.
These fields were: "Symptoms/Problems" ( $\mathrm{p}=0.03)$, "Incentives received from the dialysis team" ( $\mathrm{p}=0.02)$, "Patient satisfaction" $(\mathrm{p}=0.02)$ and "General Health" ( $\mathrm{p}=0.04)$ 


\section{Discussion}

The average age of our patients was $43.3 \pm 14.9$ years. Cisse, et al. [6] reported an average age of 50.5 years in Dakar. Ka et al. reported an average of 50.2 in Cotonou [7]. It was 48.8 years and 40.3 years respectively in Conakry [8] and Bamako [9]. The average age of our patients was broadly comparable to that of patients living in capitals of the countries of the sub-region. The DOPPS' study reports an average of 63.9 years [10]. This could be explained by the fact that end-stage renal disease affects younger populations in sub-Saharan Africa, because of the influence or the faster progression of known risk factors (high blood pressure and diabetes, etc.). Women were more represented in our study. This result seems to be corroborated by that of Cisse et al. [6] in Dakar (sex ratio $\mathrm{H} / \mathrm{F}=0.9$ ). On the other side, in the studies of Bah et al. and Diallo et al. in Conakry and Bamako, men were more numerous with a respective sex ratio of 1.15 and $2[8,9]$. The DOPPS' study also reported a male predominance [10]. Married patients accounted for $79.7 \%$ of the series. These were significantly less satisfied and had a significantly lower quality of sexual activity than the others. Libido disorders are widely reported in the literature as disabling hemodialysis patients. Seck et al. [11] reported a prevalence of erectile dysfunction of $80 \%$ in Senegalese hemodialysis patients. This difference in the quality of life between the married and the others can be explained by the fact that the married patients would relate a more real and more sustained experience of their libido state, and that the others would bring back more an impression than a real state.

The lowest average KDQOL scores were for the "occupational status" and "burden of kidney disease" fields. These are exactly the same observations made by Cisse, et al. [6] in Dakar and Yamana in Japan [12]. For Ka et al. in Cotonou [7], and Rayner et al. in the DOPPS' study [13], the "burden of kidney disease" field was also the one with the lowest score. The highest KDQOL scores were for the "Encouragement received from the dialysis team" and "Quality of the entourage" fields. These are the same observations made by Okpechi, et al. [14] in South Africa and by Mapes, et al. [15] in the DOPPS' study. Generally, studies highlight the positive effects of social support on health. It allows the patient to better cope with the negative consequences of stress and/ or illness, or even to avoid them. Patients living in the three cities had significantly different scores in the vast majority of fields explored by the SF 36 questionnaire. These differences may be explained more by the attractiveness and comfort of life in each of these cities (recreation and leisure facilities, outdoor activities, beach, and proximity to the family) than by the experience of the Kidney disease. In our study, patients who had a higher level of education had lower scores in the fields of "Encouragement received from the dialysis team", "Patient satisfaction" and "General health".

These results, far from incriminating the high level of education as hampering the quality of life of patients, should encourage us to improve, to better adapt therapeutic education to this group of patients by taking into account their high level of education, so that they feel more encouraged, more satisfied, and that their overall health improves. Clinically, patients who had residual diuresis $>500 \mathrm{ml} /$ day also had a better quality of life in several fields, compared to those with residual diuresis $\leq 500 \mathrm{ml} /$ day. Most studies show that low residual diuresis is associated with a lower quality of life and a higher risk of hospitalization and death [15-18].

\section{Conclusion}

In our study we can say that patients had the same experience of the chronic kidney disease repercussions, regardless of their place of dialysis. The lowest average scores were for the "Professional Status" (28.9) and "Burden of Kidney Disease" fields (33.3); the highest scores were "Incentives received from the dialysis team" (88.6) and "Quality of the entourage" (86.7).

\section{References}

1. WHOQOL Group (1994) Development of the WHOQOL: Rational and Current Status. Int J Ment Health 23: 24-56.

2. Thus MD, Tasmoc A, Dumea R, Hogas S, Voroneanu L, et al. (2013) A crosssectional study concerning the impact of end-stage renal disease on quality of life. Rev Medico Chir Soc Medici Si Nat 117: 908-15

3. Dikici S, Bahadir A, Baltaci D, Ankarali H, Eroglu M, et al. (2014) Association of anxiety, sleepiness, and sexual dysfunction with restless legs syndrome in hemodialysis patients. Hemodial Int 18: 809-18.

4. dos Reis Santos I, Danaga AR, de Carvalho Aguiar I, Oliveira EF, Dias IS, et al (2013) Cardiovascular risk and mortality in end-stage renal disease undergoing dialysis: sleep study, pulmonary function, respiratory mechanics, upper airway collapsibility, autonomic nervous activity, depression, anxiety, stress and quality of life: a prospective, double blind, randomized controlled clinical trial. BMC Nephrol 14: 215.

5. Fukuhara S, Lopes AA, Bragg-Gresham JL, Kurokawa K, Mapes DL, et al. (2003) Health-related quality of life between dialysis patients on three continents: The Dialysis Outcomes and Practice Patterns Study. Kidney Int 64: 1903-1910.

6. Cisse M, Gueye S, Tall A, Faye M, Niang A, et al. (2012) Quality of life of hemodialysis patients in Dakar (Senegal): what are the particularities for people living in tropical environments?. Med Sante Trop 22: 198-202.

7. Ka EHF, Vigan J, Lemrabott AT, Zohoun NE, Cisse MM, et al. (2014) Quality of Life of Chronic Haemodialytic Patients at Cotonou Teaching Hospital (BENIN). Open J Nephrol 4: 131-41.

8. Bah AO, Nankeu N, Balde MC, Kaba ML, Bah BK-H, et al. (2014) Quality of life of patients with end-stage renal disease in Guinea. Saudi J Kidney Dis 25: 1346-51.

9. Diallo D, Fongoro S, Doumbia S, Maiga H, Arama C (2011) Study of the quality of life of hemodialysis patients at the G-U Hospital in Bamako (about 30 observations). Mali Med 26.

10. Perl J, Karaboyas A, Morgenstern H, Sen A, Rayner HC, et al. (2016) Association between changes in quality of life and mortality in hemodialysis patients: results from the DOPPS. Nephrol Dial Transplant 32:521-527.

11. Seck SM, Dahaba M, Diouf B, Cisse MM, Gueye S, et al. (2011) The burden of erectile dysfunction in dialysis patients in Senegal. Hemodial Int 15: 280-3.

12. Yamana $E$ (2009) The relationship of clinical laboratory and patient parameters to the quality of life of patients on hemodialysis. Jpn J Nurs Sci 6: 9-20.

13. Rayner HC, Zepel L, Fuller DS, Morgenstern H, Karaboyas A, et al. (2014) Recovery Time, Quality of Life, and Mortality in Hemodialysis Patients: The Dialysis Outcomes and Practice Patterns Study (DOPPS). Am J Kidney Dis 64: 86-94

14. Okpechi IG, Nthite T, Swanepoel CR (2013) Health-related quality of life in patients on hemodialysis and peritoneal dialysis. Saudi J Kidney Dis 24: 519-26.

15. Mapes DL, Bragg-Gresham JL, Bommer J, Fukuhara S, McKevitt P, et al (2004) Health-related quality of life in the Dialysis Outcomes and Practice Patterns Study (DOPPS). Am J Kidney Dis 44: 54-60.

16. Park HC, Lee H, JP Lee, Kim DK, K-H OH, et al. (2012) Lower residual rena function is a risk factor for depression and impaired health-related quality of life in Korean peritoneal dialysis patients. J Korean Med Sci 27: 64-71.

17. Lopes AA, Bragg-Gresham JL, Goodkin DA, Fukuhara S, DL Mapes, et al (2007) Factors associated with health-related quality of life among hemodialysis patients in the DOPPS. Qual Life Res 16: 545-57.

18. Zyoud SH, Daraghmeh DN, Mezyed DO, Khdeir RL, Sawafta MN, et al. (2016) Factors affecting quality of life in patients on haemodialysis: a cross-sectional study from Palestine. BMC Nephrol 17: 44. 